\title{
USO DO TEXTO FILOSÓFICO EM SALA DE AULA: PARA ALÉM DA FILOSOFIA ANALÍTICA DA LINGUAGEM PELA INTERPRETAÇÃO DOS \\ ESTUDANTES
}

\author{
Adailton Pereira De Melo ${ }^{1}$ \\ Sérgio Ricardo Vieira Ramos ${ }^{2}$
}

\begin{abstract}
RESUMO
Uma das preocupações essenciais no ensino de Filosofia é a experiência da leitura em sala de aula, especialmente dos textos de Filosofia. A leitura é elemento fundante da aprendizagem uma vez que conduz, com a escrita e a oralidade, ao processo de letramento, ou seja, fazer uso social das experiências em sala de aula. Na leitura do texto filosófico, o estudante é convidado à uma experiência do texto filosófico. Nesse sentido, o presente artigo discute uma experiência em sala de aula, de leitura e interpretação de fragmento do texto de Emmanuel Levinas, "Totalidade e Infinito", em uma turma do Ensino Médio, $2^{\circ}$ ano, sem a preocupação analítica do texto, com livre interpretação dos estudantes, considerando o sentido objetivo da temática. O processo metodológico se desenvolve pela sensibilização, problematização, leitura, pesquisa de conceitos e interpretação. Muitas vezes fundamentos em discursos anacrônicos, a falta de problematização e os conteúdos de base histórica não permite aos discentes desenvolverem a sua própria capacidade de compreensão do texto, a partir de referenciais mediados pelo professor, mas não comentados pelos mesmos.
\end{abstract}

Palavras-chaves: Ensino médio; filosofia; interpretação; leitura; Levinas

\section{Introdução}

No desenvolvimento do trabalho pedagógico da disciplina Filosofia, há uma tendência de o professor desenvolver um trabalho voltado para a História da Filosofia, acentuando os aspectos relevantes e, de forma rápida, pontuando representantes por períodos, com uma ênfase na filosofia grega clássica. Por outro lado, além do fato de se estabelecer como padrão curricular uma hora aula por semana, se conta também com a dificuldade de se estabelecer um trabalho pedagógico que, mesmo contemplando as temáticas originárias da matriz curricular fornecida pela Secretaria de Educação do Estado, se possa

1 Mestrando em Filosofia - ProFilo UFPE. Email: adailtonpmelo@hotmail.com.

2 Doutor em Filosofia pela Universidade Federal de Minas Gerais, UFMG, Brasil. Professor do Colégio Aplicação/UFPE. Email: srvramos@oi.com.br 
inserir um diálogo filosófico com autores filosóficos modernos e contemporâneos.

A linguagem, em sua expressão mais superficial, ou seja, codificada, se apresenta principalmente como cadeia coerente de enunciados de identidades. A sua interpretação mais fácil e evidente é a identificação, ou seja, a reafirmação da congruência do dito consigo mesmo, a renomeação que se compraz em corresponder exatamente ao que pretende dizer em seu enunciado - o que normalmente se pode chamar precisão conceitual, o que acontece quando "algo" é identificado como "algo", "isso" é identificado com "isso", segundo Souza (2000) sob a perspectiva da filosofia de Levinas.

Mas a linguagem é também um sistema de nomes. O trabalho se justifica pela necessidade de se impor a fluência verbal ou temporal da sensação, a denominação que designa ou constitui identidades. Através da claridade que a temporalização abre ao sensível, ao descobri-lo por seu próprio passado e ao reuni-lo mediante a retenção e a memória, ou seja, em Lévinas, a palavra é nominação tanto quanto denominação ou consagração "disto como isto" ou "disto como aquilo" - dizer que é também entendimento e escuta absorvidos no dito, obediência no seio do querer ("pretendo dizer isto ou aquilo"), kerigma no fundo de um fiat. Antes de toda recepção, um já dito anterior às línguas expõe a experiência ou a significa (propõe e ordena) em todos os sentidos do termo, oferecendo assim às línguas históricas faladas pelos povos um lugar, permitindo-lhes orientar e polarizar a seu gosto a diversidade do tematizado (SOUZA, 2000).

Nesse sentido, o trabalho tem como objetivo o uso do texto de Levinas (fragmento) Totalidade e Infinito, considerando que a identificação não é o fruto de uma arbitrariedade qualquer, mas a expressão de um instante inconfundível, o momento do acontecimento que se autoconsagra, ao consagrar, pela linguagem dita, é também o real percebido, o que faz com que todo dito ou enunciado, antes de ser meramente dito ou enunciado, seja desde sempre já dito, já dado que assume consciência de realidade.

A identificação e compreensão não é conhecimento, mas ganha o status de reconhecimento, conhecimento qualificado pela congruência (identificatória) entre o conceito e o que ele designa em um determinado âmbito de significação, pois "a identificação é kerigmática”. 


\section{O texto filosófico em sala de aula}

O ensino da Filosofia deve promover o contato com os conhecimentos filosóficos na sala de aula do Ensino Médio, para que isso ocorra de modo profícuo, o contato com o texto filosófico torna-se fundamental, o que conduz o estudante a fazer uma experiência filosófica a partir da sua apropriação do texto, ideias, de situações-problemas e de questionamentos críticos.

Um elemento fundamental no ensinar e aprender a filosofar em sala de aula, que, como concorda Matos e Costa (2014) é um desafio permanente na prática pedagógica dos professores de filosofia neste século XXI, se traduz na ausência de conhecimento filosófico nas escolas, ou seja, nas aulas de filosofia. Depreende-se daí alguns aspectos que são pontuados em sala de aula como a ausência de interesse por parte dos estudantes, a simbiose dos conteúdos centralizados em determinados autores clássicos e em discursos anacrônicos, a falta de problematização e os conteúdos de base histórica que não permite aos discentes desenvolverem a sua própria capacidade de compreensão do texto, a partir de referenciais mediados pelo professor, mas não comentados pelos mesmos. O resultado é que o assunto fica tão desinteressante que se perguntam por que e para que estudar filosofia. Acompanha essa dinâmica, o fato do ensino de filosofia ser ministrado por professores que tiveram contato com a disciplina através da Introdução à Filosofia ou Filosofia da Educação, ou mesmo Fundamentos Sócio Filosóficos da Educação, sem um conhecimento profundo do conteúdo filosófico, mesmo que seja apenas sob o enfoque da História da Filosofia. Acresce-se que alguns docentes assumem a tarefa do ensino com formação em outras áreas como História, Geografia, Letras, tendo como referência para o ensino, apenas os conteúdos desenvolvidos nos livros didáticos.

Há de se considerar que o ensino de Filosofia no Ensino Básico é uma contribuição à inovação na educação, na possibilidade de melhoria didáticopedagógica das condições de aprendizagem não somente na área de Filosofia. Ao se trabalhar a dinâmica da leitura e da interpretação, o estudante passa a desenvolver melhor o hábito da leitura, ao se fazer uma análise de uma situação, lhes é permitido inferir uma análise crítica na literatura. Os conceitos de lógica formal permitem que os mesmos aprimorem a capacidade de refletir com coerência e coesão. De modo geral, a Filosofia contribui para que o olhar 
do estudante esteja atento ao caráter e dinâmica ideológica que faz com que a escola seja um instrumento de reprodução da ideologia do poder, muito mais que um espaço criativo para a formação cidadã e a produção de conhecimento.

Não se pode prescindir do fato de que a filosofia é "explicitação e discurso" (GOLDSCHMIDT, 1963, p. 140), constituindo-se enquanto interpretação como reaprendizagem e, como explicitação, elemento constitutivo e necessário para o desenvolvimento da intuição do estudante.

Entende-se que a leitura e análise do texto filosófico em sala de aula são ponto de partida, meio de se praticar filosofia, considerando que a apreensão dos textos filosóficos contribui significativamente para o desenvolvimento do pensamento, da discussão, da argumentação, contidos nas entrelinhas dos textos e que deve possibilitar a criação e a recriação dos conceitos filosóficos pelos estudantes. Acrescente-se que o contato com o texto permite o exercício da filosofia e evita a corrupção de uma interpretação ou comentário realizado pelo professor, intérprete ou comentarista de um determinado filósofo, mesmo que não se dispense a possibilidade do seu uso ao final, de modo que seja responsável por uma síntese do trabalho desenvolvido pelos estudantes.

Para entender a função do texto filosófico em sala de aula é importante compreender que primeiro se faz necessário saber qual o texto a ser escolhido como resposta a uma problematização, advinda de uma temática curricular e definida ou eleita pelos estudantes em sala de aula; segundo, o texto deve ser filosófico e conduzir ao diálogo em sala de aula, a partir do confronto com o problema colocado, considerando a dimensão da temática do currículo oficial, mas sem se prender necessariamente a ele, tais como ética, politica, estética, filosofia da linguagem, entre outros.

Existe algo atrás da linguagem para ser desvelado, descoberto por nossa consciência? Ou seria ela, também, formadora e parte desse real do qual aparece simplesmente como acessório? Partindo do pressuposto de que a linguagem não é somente um acessório estético, mas se ela forma a compreensão que temos do real, é necessário uma compreensão de como esta se forma e que imbricação ela nos dá nas fontes, em nossos textos e em nosso trabalho, na própria compreensão da realidade, nas relações com o outro. 
É possível entender a língua como elemento político, capaz de intervir no mundo social e, ao mesmo tempo, base para a formação e compreensão da maneira como o indivíduo percebe e é compreendido pelos seus contemporâneos. Apreender e refletir a partir da linguagem é o processo de formação de conceitos, que engendra, necessariamente o diálogo e que conduz ao eixo de interpretação do signo linguístico e do seu significado no contexto das aprendizagens significativas em sala de aula.

Conduzir os alunos a refletir sobre a dimensão da linguagem como processo linguístico e constructo de sentidos para um diálogo no âmbito da aprendizagem filosófica significa conduzir o discurso para o confronto com o texto, seja ele filosófico ou não, desde que se garanta o seu sentido reflexivo, critico, na perspectiva da filosofia da linguagem, numa perspectiva querigmática, daí a escolha de Levinas como texto de confronto.

\section{Apropriando sentidos do texto}

A escolha de um texto filosófico a ser trabalhado em sala de aula não pode deixar de considerar uma breve introdução, contextualização da produção filosófica, mas não pode se reduzir à mesma, assim como o professor não pode ser o comentador ou promotor da análise textual, sob o risco de inibir a possível intervenção dos estudantes na apreensão do texto, na elaboração de conceitos e no confronto de ideias. O texto não pode ser meramente ilustrativo de um período da História da Filosofia, assim como não pode ser reduzido à ilustração temática proposta pela estrutura curricular escolar.

Nossa ideia é que depois de iniciar com a sensibilização ao problema, passando pela fase de problematização, quando as questões já estiverem no poder dos alunos, o próximo passo é o de começar o estudo filosófico para dar conta do problema levantado. E este estudo se dá através dos textos filosóficos" (ASPIS ; GALLO, 2009, p. 94).

Dois aspectos chamam a atenção, que se faz necessário uma problematização e que o texto filosófico deve ser o fio condutor do discurso e do confronto entre realidade apropriada pelos estudantes e o texto filosófico. Nesse caso, não se pode reduzir a leitura do texto a qualquer texto. O texto deve ter uma relação dialógica com a problematização. 
Aspis e Gallo (2009) chama a atenção para o processo de leitura do texto filosófico em relação ao confronto com a problematização colocada como temática ou ponto de partida da aprendizagem filosófica em sala de aula, ou seja, não deve o professor explicar o texto ou comentá-lo, sob o risco de cair em reducionismo ou imposição de uma determinada leitura. "A explicação é um outro texto, é um discurso inventado pelo professor sobre o texto em questão" (ASPIS; GALLO, 2009, p.18).

Ao contrário, mesmo o professor elegendo o texto, ele o faz para que este seja o mediador da reflexão, do confronto, do discurso, da possibilidade de ser explorado, esmiuçado pelos estudantes.

A leitura filosófica é a busca exploratória dos significados e significantes, das relações semânticas, do desvelamento das metáforas e das analogias, de saber que o texto filosófico está falando ou que e a quem está respondendo.

Koch e Elias acentuam que:

A leitura é uma atividade de construção de sentidos que pressupõe a interação autor-texto-leitor, é preciso considerar que nessa atividade, além dos pontos de sinalização que o texto oferece, entram em jogo os conhecimentos dos textos (KOCH; ELIAS, 2014, p.37).

O processo de atividade de leitura é, na verdade, um exercício de pensamento que envolve estratégias sócio cognitivos, o que significa, segundo Koch e Elias (2009) a mobilização de tipos de conhecimento armazenados na memória, ao mesmo tempo em que o estudante processa recortes que ajudam a mobilizar hipóteses interpretativas. O significado é o desenvolvimento de conhecimentos linguísticos, enciclopédicos e interacional que permitirá a interpretação para a produção do discurso, a compreensão do conceito e a discussão filosófica em sala de aula.

Obviamente, que os termos filosóficos não fazem parte do cotidiano do estudante, mas se pode partir do princípio de que, ao se considerar os termos em sua intensão e extensão se possibilita uma compreensão imediata. "A intensão é definida como sendo o sentido e o significado de um termo, ou seja, a compreensão que um termo tem, ao passo que a extensão de um termo é a classe de todas as entidades às quais se pode aplicar o termo corretamente." (MARCUSCHI, 2007, p.112). Nesse sentido, no texto filosófico se trabalha 
com as características remetentes à extensão do termo utilizado e ao mesmo (intensão) e, ao mesmo tempo, se percebe a extensão do texto pela identificação do autor.

\section{A interpretação do texto de Levinas em sala de aula}

Em sala de aula, o uso do texto filosófico foi realizado para a construção de sentidos para o estudante. Não pode ser uma hermenêutica pura oferecida pelo professor, porque não se situa no âmbito da compreensão histórica do autor e de seu texto. Por outro lado, não se trata apenas de uma ação linguística reduzida à gramática e ao léxico, embora não se possa desprezar esses últimos, haja vista que são "determinantes na construção da coerência e da relevância dos sentidos ativados" (ANTUNES, 2010, p.16).

A análise do texto filosófico consistiu em um não reducionismo a um trabalho hermenêutico, muito embora hermenêutica e interpretação tenham a mesma origem grega, conforme define Schmidt (2016). A hermenêutica implica (conforme se percebe em Schleiermach, Gadamer e Dilthey) como a descoberta da decisão seminal do autor e, "compreende como o autor desenvolve seu pensamento sobre este assunto", bem como, "analisar como o autor expressa suas ideias no texto (SCHMIDT, 2016, p. 43).

Nesse sentido, o trabalho com Levinas $(2004 ; 2008)$ em sua Ética da Alteridade, tornou-se uma das questões fundamentais no século XXI; é a produção do sujeito como senhor absoluto de sua vida e capaz de não apenas dominar a natureza, mas tomar posse do outro, coisificando-o, dominando-o. Essa concepção foi trabalhada por Karl Marx a partir das relações de poder, dentro do sistema de produção capitalista. No caso, essa relação de poder se institui no âmbito das relações educativas, na escola, em sala de aula (QUIJANO, 2005). Isso significa que na organização escolar vigoram tanto poderes instituídos, por quem de direito, como poderes instituintes atualizados pelos atores organizacionais, neste caso, sobretudo os estudantes.

O ensino de Filosofia, por sua vez, inserida no contexto de aprendizagem dos estudantes na educação básica, no caso especifico do Ensino Médio é um fundamental e importante instrumento de preparação e formação dos jovens e adolescentes para o exercício do espírito crítico, do poder da argumentação, da mesma forma que uma compreensão ampla e abrangente da 
complexidade da vida humana, sob a perspectiva de uma formação ética (SANCHEZ VAZQUEZ,2014).

Gallo (2016, p. 336) orienta que a filosofia tem caráter ativo, tem uma finalidade de convidar e estimular os estudantes "para que eles criem seus próprios conceitos, ou ao menos reelaborem criativamente os conceitos com os quais terão contato”. Para o autor o processo de construção do pensamento passa, necessariamente por um processo de sensibilização, seguido depois de uma problematização, da investigação sobre o sentido experimentado na realidade factual e, por fim, o estabelecimento do processo de conceituação que deve ser, ao mesmo tempo, a assimilação da ideia do autor, mas também de uma possibilidade de criação de uma consciência, no caso do texto de Levinas, de uma consciência ética.

Experimentar o pensamento refazendo percursos do pensamento dos filósofos, sendo capazes de dialogar com os textos, de neles encontrar ferramentas conceituais para enfrentar os problemas que estamos investigando. Essa é a meta da etapa de conceituação, que finaliza os quatro passos didáticos de um aprendizado ativo da filosofia (GALLO, 2016, p.337).

Levinas em sala de aula conduz, necessariamente, a uma ação educativa que deve promover a criação de um conceito de alteridade, numa perspectiva de fundamentar uma práxis ética que deve ter início nas ações, ou uma práxis dos estudantes entre si e nas relações com todo os Outros que fazem parte do universo escolar. Dessa forma, a educação filosófica em sala de aula, "adquire no horizonte da ética da alteridade a feição de uma sabedoria que, como tal, interrompe e ultrapassa todo saber ou conhecimento a priori de cunho teórico ou prático que se pretenda a respeito do outro e do que se deve fazer a ele" (RIBEIRO JÚNIOR, 2011).

Assumir o texto como ponto de partida para a construção da alteridade é uma dimensão que conduz ao infinito, presente em cada momento, tempo e espaço nesse mundo (LEVINAS, 2008), considerando que a primeira fonte da moral, que se refere a uma primeira infância da humanidade: a moral do egoísmo, do si a si, tanto individualista como totalitário. Nesse sentido, a educação escolar deve conduzir, necessariamente, na perspectiva de Levinas (2004), o reconhecimento e aceitação que o outro, como diferente, provoca no eu e na sua pretensão de tentativa de assimilação do outro, o outro em si mesmo, ouvir o Outro como dizer. A nova humanidade nasce da ética da 
alteridade, e esta, por sua vez, se erige como nova moralidade que implica em ouvir e viver o Outro como outrem e não como condição egoísta do eu.

Para Antunes (2010, p.18) todo e qualquer texto significa o resultado de elementos característicos e contextuais, o que significa funcionar como parte de um evento comunicativo, ao mesmo tempo em que resulta do conhecimento do mundo (problematização) atuando pelo "conjunto de elementos contextuais e textuais", ou seja, dá-se numa relação dialógica entre leitor,- texto - problema filosófico, seja ele existencial, circunstancial ou empírico oferecidos pelos estudantes como ponto de partida na sensibilização e apresentação/eleição do problema a ser discutido.

O professor, nesse caso, não pode e não deve ser o explicador do texto, mas deve dialogar com texto, a partir da leitura e reflexão realizada pelos estudantes, sem a intervenção inicial comentada pelo docente. Isso é entendido como o exercício do pensar o texto filosófico pelo texto em si e sob a perspectiva do que ele oferece como condição de um determinado problema apresentado pelos estudantes, como por exemplo, uma questão ética (corrupção no Brasil, dentro da temática curricular de ética ou mesmo de Filosofia Política).

O pensar é um pressuposto à formação humana, como possibilidade do aprendizado dos modos de olhar, de conceber o mundo, de construir um ponto de vista; é aprender com a Filosofia a alcançar uma perspectiva, capaz de nos encantar na leitura do mundo, situarnos nele om certa autonomia (MATOS ; COSTA, 2014, p. 120).

Nesse caso, observa-se que o texto de Levinas conduz à textualidade, ou seja, uma característica estrutural das chamadas atividades sócio comunicativas que também são linguísticas e são executadas entre os processos de comunicação, o que significa que "nenhuma ação da linguagem acontece fora da textualidade" (ANTUNES, 2010, p. 29), mesmo o texto filosófico.

O texto é a expressão de algum propósito comunicativo e a ele recorrese como atividade funcional, no sentido de que tem uma finalidade para a qual o leitor recorre, como um objeto especifico, no caso do texto filosófico em sala de aula, é o lume do confronto oferecido aos estudantes às suas expectativas, problematizando-os sobre as experiências factuais. 
Nesse sentido, a problematização não pode partir do princípio de que o texto já é uma tentativa de se esperar dos discentes uma resposta pela qual o professor já a tem como pressuposto.

O texto implica em uma expressão verbal de uma atividade social de comunicação, mesmo que filosófica, que envolve um parceiro, ou seja, o interlocutor, o que implica em certo dialogismo, já pensado e reconhecido por Bakhtin (1995). Segue-se a esse princípio, o fato de que todo texto filosófico deve se caracterizar por uma orientação temática, o que significa que o texto se constrói a partir de um tema, de um tópico, de uma ideia central, de um núcleo semântico que lhes dá condições de continuidade, unidade, comparação e que implica em outros critérios de textualidade tais como a coesão, a coerência, a intencionalidade, a informatividade e a situacional idade (ANTUNES, 2010; FOLSCHEID e WUNENBURG 2006).

\section{A intervenção em sala de aula}

O processo se iniciou com a sensibilização, através da qual, os estudantes foram convidados para uma avaliação do sentido da ética, da alteridade e do atual contexto escolar e de sala de aula.

O segundo momento consistiu na apresentação do texto de Emanuel Levinas, Totalidade e Infinito, trecho retirado das páginas 24 e 25, o qual descreve o sentido da alteridade e a identificação do eu com o Outrem.

Depois da leitura do texto, os estudantes levantaram questões de interpretação respondendo às questões: o que eu entendo do texto? $\mathrm{O}$ que o autor quer falar para mim, hoje? Qual (is) lição (ões) para nossa vida de relacionamento com o outro? Em que sentido o texto pode nos servir de orientação para nossas vidas?

As questões coletadas foram agrupadas e discutidas em grupos, ficando cada grupo com um relator, um coordenador da discussão e um avaliador da participação. Os relatórios seguiram para apresentação/socialização em outra aula.

Dos relatórios desenvolvidos pelos estudantes, algumas das questões foram colocadas em forma de um relatório geral do qual se extrai o seguinte texto: 
Não pensamos em sentir sozinho no mundo. Nossos sonhos e nosso pensar no futuro nos leva a compreender que não estamos sozinhos e que precisamos uns dos outros. [...] o encontro que temos conosco mesmo é porque aprendemos que o outro, apesar de ser diferente, podemos chama-lo de amigo, sabendo que o outro tem limites tanto quanto eu, mas que não permite que exijamos que ele seja como queremos. [...] O outro tem que ser compreendido como o outro diferente de nós, mas complemento da nossa existência enquanto outro. [...] (GRUPO 1 e 2).

Eu ganho sentido como ser humano à medida que tomo consciência que estou em processo de construção e isso significa aceitar o confronto oferecido pelo outro ou outros [...]. Observamos quando o autor diz (p.250 que o outro recusa-se a aceitar ser dominado por mim, ao mesmo tempo capaz de contestar-me enquanto sujeito em construção. (GRUPOS 3 e 4).

O texto de Levinas, na avaliação dos estudantes, flui em uma linguagem comunicativa de fácil entendimento e atualidade, respondendo às questões contemporâneas, frente às tragédias do cotidiano que inclui intolerância, violência, solidão, egoísmo e individualismo. A proposta parte do ser no sentido verbal e supõe uma abertura sobre as condições em que vivemos nos dias de hoje, muito embora a própria escola não permita, através de sua política fomentar as experiências comunitárias, uma vez que a competição, o controle, a violência moral é a marca da gestão escolar.

\section{Considerações finais}

Conclui-se que, a leitura reflexiva ou comprometida é aquela que realiza a análise cuidadosa de textos, na qual sustenta sua consistência, mas anima a apreensão da singularidade de cada filosofia como uma espécie de parceria, incorporando a reflexão e o ponto de vista do estudante, sem passar pela interpretação hermenêutica clássica ou pelos comentários do professor.

Com relação à criticidade diante da leitura e interpretação, verificou-se uma melhoria com relação à disposição para analisar o texto e aprofundar nas observações. Isso porque sempre sugerimos que os discentes promovessem a reescrita, com a reflexão do grupo, suas compreensões e resultados das pesquisas.

Da leitura do texto de Levinas, segue-se o debate, pois permite a ampliação do olhar dos estudantes para a compreensão do texto, permitindo que criem gosto pela pesquisa e pela leitura, de modo que possam se posicionar de maneira mais efetiva. Nas atividades de produção textual, os 
alunos começam a demonstrar maior cuidado com a opinião do grupo, uma vez que perceberam que o texto de Levinas implicava na realização do eu como encontro com o outro, como possibilidade de confronto com a realidade do próprio eu, desprovido de suas facetas egoístas, totalitárias, entre outros. Os trabalhos realizados no ambiente virtual do site, após a análise do texto, permitiram um maior contato com as novas tecnologias, ampliando a interação e a troca de experiências entre os discentes.

No uso do texto filosófico em sala de aula, o estudante é convidado a aprender praticando, experimentando o pensamento em sua fonte. Nesse sentido, a filosofia é o pensar reflexivo do homem sobre o seu cotidiano para compreender os seus atos e seus pensamentos. Contudo, não se trata de qualquer reflexão, mas o refletir sobre próprio pensar, o que pressupõe o contato com o texto, ou seja, pensar o já pensado, voltar para si mesmo e colocar em questão o que já se conhece.

\section{Referências}

ANTUNES, Irandé. (2010) Análise de textos: fundamentos e práticas. São Paulo: Parábola Editorial.

ASPIS, Renata Lima; GALLO, Silvio. (2009) Ensinar filosofia: um livro para professores. São Paulo: Scipione.

BAKHTIN, Mikhail. (1998) Os gêneros do discurso. São Paulo: Editora 34.

FOLSCHEID, Dominique; WUNENBURG, Jean Jacques. (2006) Metodologia filosófica. São Paulo: WMF Martins Fontes.

GALLO, Silvio. (2016) Filosofia. Experiência do pensamento. São Paulo: Scipione.

GOLDSCHMIDT, Victor. (1963) A religião de Platão. São Paulo: Difusão Europeia do Livro.

KOCH, Ingendore Villaça; ELIAS, Vanda Maria. (2014) Ler e compreender: os sentidos do texto. São Paulo: Contexto.

LÉVINAS, Emmanuel. (2004) Entre nós: ensaios sobre a alteridade. Petrópolis: Vozes. . (2008) Totalidade e infinito. São Paulo: Edições 70.

MARCUSCHI, Luiz Antônio. (2007) Fenômenos da linguagem. Rio de Janeiro; Lucerna. v. 1.

MATOS, Junot Cornéliio; COSTA, Marcos Roberto Nunes (orgs). (2014) Ensino de filosofia: questões fundamentais. Recife, Editora Universitária da UFPE. 
Perspectiva Filosófica, vol. 44, n. 2, 2017

QUIJANO, Aníbal. (2005) Colonialidade do poder: eurocentrismo e América Latina. Buenos Aires: CLACSO.

RIBEIRO JÚNIOR, Nilo. (2011) Ética e alteridade: a educação como sabedoria da paz. In: CESCON, Everaldo; NODARI, Paulo César (org). Filosofia, ética e educação: por uma cultura de pa‡. São Paulo. p. 73-115.

SCHMIDT, Lawrence K. (2016) Hermenêutica. 3.ed. Petrópolis: Vozes.

SOUZA, R. T. (2000) Sentido e alteridade: dez ensaios sobre o pensamento de Emmanuel Levinas. Porto Alegre: EDIPUCRS. 